\title{
Forgiveness and Personality Type among Men and Women Suffering from Cardiovascular Diseases
}

\author{
Elham Foroozandeh 1
}

\begin{abstract}
Background: Role of personality and some components of behaviors, traits and emotions as effective factors on coronary heart diseases (CHD) were presented nearly 50 years ago with the concept of "type A" behavior, a compound of hostility, impatience, competitiveness and dominance. Later studies showed crucial role of other traits and behaviors like anger, introversion, depression and forgiveness. Objective: The aim of this study was to compare personality type and forgiveness in the patients suffering from cardiovascular diseases based on gender. Materials and method: The cross sectional study was designed and sample was collected from men and women referred to cardiologists (within the age range of 23-75 years old) from the patients of Shahid Rajaee Heart Hospital of Tehran, Iran from December 2010 to March 2011. Total 87 subjects were selected using random method. The study subjects were given two questionnaires: personality type A (with two factors: TA1, pathologic behaviors of type A personality and TA2, non pathologic behaviors of type A personality) and Interpersonal Forgiveness Inventory (IFI), with three subscales namely reestablishment of relationship, control of revenge and realistic perception. Data were analyzed using SPSS software. Results: Mean $( \pm S D)$ age of men was $50.5 \pm 11.6$ years $(n=33)$ and $55.7 \pm 14.4$ years in women $(n=54)$. Mean duration of suffering from cardiovascular diseases in men was 7.8 years and in women was 9.10 years. The study found high mean scores of type A pathologic but not non pathologic type A among women compared to men $(p<0.038)$ and no statistically significant differences in forgiveness subscales. Conclusion: The study revealed significant difference between women and men suffering from cardiovascular disease in pathologic type $A$ (TA1) and negative relationship between pathologic type $A$ and forgiveness.
\end{abstract}

Keywords: Forgiveness; personality type A; cardiovascular disease.

$$
\text { Delta Med Col J. Jul 2014;2(2): } 48 \text { - } 52
$$

\section{Introduction}

Although the reverse relationship between health and negative personality traits such as anger and hostility are mentioned by behavioral and medical researchers for many decades, researchers have recently searched the relationship between health and positive mental qualities such as forgiveness, sympathy and optimism. ${ }^{1-3}$ Forgiveness is one of the positive structures and an intentional act to stop anger and hatred toward an offender. Thus, through this intentional act, the victimized person, instead of negative emotional reactions, replaces emotional characteristics like affection, perception and sympathy. ${ }^{4}$ Also, thanks to heavenly teachings and those presented by various religions, human community has always faced recommendation for forgiveness. This quality has always induced positive and prominent aspects to human nature. In theoretical view, forgiveness as a human trait has always belonged to the domain of theology and religion. However, now a days, it has entered into psychology bearing a unique concept.

1. Assistant Professor, Department of Psychology, Isfahan Science and Research Branch, Islamic Azad University, Isfahan, Iran.

Correspondence: Elham Foroozandeh. e-mail: Elham_for@yahoo.com 
Enright et al. 5 have defined forgiveness as follows: ability to reject and to put affection and negative judgment aside about a wrong act that is committed by an individual against us and replacement of negative emotions with kindness, affection and sympathy. In more recent researches, forgiveness is defined as an intentional act for stopping anger and hatred against the offender. In this way, the victimized person replaces negative emotional reactions with emotional qualities of affection, perception and sympathy. 6 Some researchers consider forgiveness a collection of emotional changes, which are made after an inter individual threat, attack or hurt. Here, the victimized person is rejecting his will for revenge, i.e. decline of negative emotions associated with non forgiveness: wrath, hatred and hostility and simultaneously, positive emotions of sympathy and affection presenting a positive affection related to forgiveness. ${ }^{7}$ One of the briefest definitions of forgiveness is "Discarding revenge by the victimized person and putting anger against the offender aside". 8

In a study conducted on the patients suffering from chronic pain, it has been found that the patients who have obtained higher grades with respect to forgiveness have reported lower levels of pain, anger and helplessness. Forgiveness can release an individual from negative emotions and help body immunity system. ${ }^{4}$ Moreover, results associated with recording electromyogram (EMG), skin reaction, average of blood pressure and heart rate during forgiveness are lower compared to conditions without forgiveness. ${ }^{7}$ In addition, quality of forgiveness is a good prediction for diastolic blood pressure and it can have an effective role in lowering of this type of blood pressure. It seems that cardiovascular complications caused by stress are subsided upon raise of forgiveness. Forgiveness leads to decrease of general level of blood pressure accordingly. In a research entitled "Forgiveness and mental health variables", it has been revealed that higher level of forgiveness has statistically meaningful relationship with low psychotic levels. Moreover, being extrovert (friendly relations or assertiveness), sense of responsibility and openness toward experiences (visualization and rationalism) is related to forgiveness of oneself and others. These elements are more displayed among men. ${ }^{9}$
Clinical observations reveal that many patients suffering from chronic pain have problems in forgiveness of the persons who committed a mistake against them. These patients are on this opinion that others have abused them unfairly. In a study done on 61 patients suffering from chronic pain, it has been found that these patients have shown noticeable differences in forgiveness dimensions. The patients who have obtained higher grades have reported lower levels of pain, wrath and helplessness. Moreover, it has been found that the variable of "wrath" has a determinant role in forgiveness and pain. The aforesaid findings have implicitly revealed that inner wrath as a result of non forgiveness in a long period, shall bring about negative emotions. 4 According to another research, it was requested to participate in a test of visualization of two situations, one without forgiveness (being damaged and having hatred) and another with visualization of forgiveness in connection with an offense committed against them where they were victimized. The results associated with recording EMG, skin reaction, arterial pressure average and heart beat during the situation without forgiveness were higher more than that situation with forgiveness. ${ }^{7}$

Although forgiveness structure has recently been put forth in the realm of psychology, many years ago, in 1960, Freedman and Rosenman, two cardiologists, had found that the individuals who were referred to them for heart surgery and removal of coronary stenosis have similar personality qualities. Unofficial observations of Freedman and Rosenman have presented a base for official assessment of "A" model. Against forgiveness as a concept in positive psychology, Type A and type D personality characteristics have been recognized as a predictor for emergence of cardiac complications. 10,11 The behavioral model of type A is identified based on effort for competitive progress, feeling of impatience and time pressure, tendency toward hostile and aggressive behavior. If an individual with type A personality trait tries to achieve an objective, he/she is not willing to face any obstacle preventing him/her. If an obstacle appears, he easily puts it away. These persons speak fast, walk fast and eat fast. They are impatient and 
ambitious. They show exaggerated perfectionism. They work exceedingly and on a whole, they experience a stressful life. 12 Freedman and Rosenman called these individuals as those with personality type A. Competition, time emergency and anger are regarded as the most important and common characteristics in this kind of personality type. Feeling of non-satisfaction with life is observed among these individuals. From among other significant qualities of the said individuals, one can point out the great importance they attach to work. They show a tendency toward management and leadership and attach great importance to material things more than human issues and relations. Quality of life among the individuals of type A is very low. They are involved in several jobs in the respective unit. They have a low threshold of irritation. Time is of great importance for these individuals. However, they are not able to use time due to low quality of their life. They make exaggerated efforts to obtain more points. They are always seeking for more success. The results of researches on this life achievement have revealed this reality that this kind of personality type makes destructive and destroying effects on the structure and physiology of body. The individuals of personality type A are more in excitation or sympathetic mode rather than parasympathetic and relaxation. ${ }^{13,14}$

The aim of this study was to compare personality type A and forgiveness in male and female patients suffering from cardiac disorders.

\section{Materials and method}

Concerning the fact that the aim of this study was to compare personality type A and forgiveness in the patients suffering from cardiac disorders based on gender, a sample was selected from among women and men referred to cardiologist (within an age range of 23-75) with a volume of 87 persons. The sample was selected using random method from the patients of Shahid Rajaee Heart Hospital in Tehran, Iran, from December 2010 to March 2011. After achievement of their collaboration, they were given two questionnaires for assessment of personality type A (a form with 24 questions) and interpersonal forgiveness inventory (IFI), with three subscales namely realistic perception, control of resentment and reestablishment of relationship.

Personality type A questionnaire: A self report scale with 24 items were developed by Najarian et al. 15 in a sample with 328 persons of students in Iran. Factor analysis has shown that 16 items are located on factor 1 (TA1) and 8 items are put on factor 2 (TA2). Subscale TA1 (type A pathologic) is more related to morbid aspects (such as aggression, anxiety and low self esteem), while the element of TA2 (type A non pathologic) is mostly related to non morbid aspects such as tendency toward success and hard work and high self confidence of behavioral model of Type A. Scoring of the this scale is on Likert system and one of the four options of "never", "rarely", "sometimes" and "most often" were given to be selected and were graded based on scales of " 0 ", "1", "2", "3". Verdi et al. have achieved final coefficients of the first and second factors as 0.78 and 0.61 .16

Evidence validity simultaneous with scores obtained from the two questionnaires of personality type A and Beck Depression Inventory (BDI) the correlation between factor 1 of type $A$ and depression was 0.56 and the correlation of the second factor of type A and depression was -0.16 and both of them were statistically meaningful. 16

Interpersonal Forgiveness Inventory (IFI): IFI has been chosen from the thesis of doctorate of psychology written by Ehtesham and it has assessed interpersonal forgiveness. It consists of triple elements as reestablishment of relationship, control of revenge and control of resentment, and realistic perception. For scoring the 25 items of these inventory four choices of "completely disagreed, "disagreed", "agreed" and "completely agreed" were considered scoring "4", "3", "2" and "1" respectively. Maximum score which can be achieved from this scale is 100 and the minimum is 25. Except for one general grade for this scale, three scores related to subscales, reestablishment of relationship, control of revenge and control of resentment and realistic perception are obtained. Maximum score that can be achieved for the first subscale is 48,24 for the second subscale, and 28 for the third subscale. Obtaining a high score in the 
subscale of reestablishment of relationship and control of revenge (the first element) indicate great ability of the individual for reestablishment of relationship with the offender and his low tendency for hatred and revenge against the mistakes made by others. Those have obtained high grade in the subscale of control of resentment (the second element) are probably those individuals who deal less with rumination of thoughts related to their victimization. Achieving high scores at the subscale of realistic perception (the third element) also reveals the ability to perceive human qualities (like probability of offending) and conditions for occurrence of mistake and capability of sympathy with the offender. 17

\section{Results}

Total 87 subjects were included in this study. Among them 54 were female and rest were male. After gathering data, comparison between women and men suffering from cardiovascular disorders has been conducted using MANOVA analysis.

Table I is related to descriptive statistics of two groups. First, second and third variables are subscales of forgiveness and the others are pathologic (TA1) and non pathologic (TA2) types of "A" model.

Table I: Distribution of subscales of forgiveness and TA1 and TA2 in men and women suffering from cardiovascular diseases $(\mathrm{N}=87)$

\begin{tabular}{lcr}
\hline Variables & \multicolumn{2}{c}{ Gender } \\
& Female $(\mathrm{n}=54)$ & Male $(\mathrm{n}=33)$ \\
\hline Forgiveness (Mean \pm SD) & & \\
$\quad$ Reestablishment of relationship & $31.56 \pm 6.306$ & $31.82 \pm 6.049$ \\
$\quad$ Control of revenge & $16.17 \pm 3.051$ & $16.52 \pm 3.572$ \\
$\quad$ Realistic perception & $18.85 \pm 2.602$ & $19.03 \pm 2.733$ \\
Type A personality (Mean \pm SD) & & \\
TA1 & $26.43 \pm 5.534$ & $23.55 \pm 7.116$ \\
TA2 & $12.65 \pm 3.827$ & $13.27 \pm 4.811$ \\
\hline
\end{tabular}

Table II shows the findings of MANOVA and comparison of means between men and women. There is no statistical difference between mean of reestablishment of relationship $(\mathrm{F}=0.037 ; \mathrm{p}=0.849)$, control of revenge $(\mathrm{F}=0.234 ; \mathrm{p}=0.629)$ and realistic perception $(\mathrm{F}=0.093 ; \mathrm{p}=0.761)$ in male and female subjects, i.e no meaningful gender predilection regarding forgiveness (IFI).
Table II: Comparison of subscales of forgiveness and Type A personality in women and men

\begin{tabular}{lcccc}
\hline Dependent Variable & $\begin{array}{c}\text { Mean } \\
\text { square }\end{array}$ & $\begin{array}{c}\text { F } \\
\text { value }\end{array}$ & Significance & Observed Power \\
\hline $\begin{array}{l}\text { Reestablishment of } \\
\text { relationship }\end{array}$ & 1.413 & .037 & .849 & .054 \\
Control of revenge & 2.487 & .234 & .629 & .077 \\
Realistic perception & .652 & .093 & .761 & .060 \\
TA1 & 169.948 & 4.454 & .038 & .550 \\
TA2 & 7.990 & .448 & .505 & .101 \\
\hline
\end{tabular}

According to the aforesaid table, there is a statistically meaningful difference between women and men suffering from cardiovascular disease in pathologic type A (TA1) but not in non pathologic type A (TA2). Correlation coefficient was also done among variables in the two groups of women and men which revealed that there is negative meaningful correlation between pathologic type A with the subscale of realistic perception (for women, $\mathrm{r}=-0.63 ; \mathrm{p}<0.002$ and for men, $\mathrm{r}=-0.617$; $\mathrm{p}<0.006)$. Although pathologic type A has a negative correlation with other two subscales of forgiveness, the calculated correlation coefficient is not meaningful in statistical point of view.

\section{Discussion}

No meaningful difference was found between women and men suffering from cardiovascular diseases in forgiveness subscales and non pathologic type A which is related to tendency toward success, hard work and high self confidence. Although regarding the subscale of reestablishment of relationship, women have acted better than men, with respect to the subscales of control of resentment and realistic perception they were at lower level indicating a little difference (which was not statistically meaningful). Compared to normal individuals and those suffering from cardiac disorders, this point has repeatedly been confirmed in previous studies that the difference between the individuals suffering from coronary heart disease (CHD) is related to type $\mathrm{A}$ and the behaviors associated with this personality type. 14 However pathologic type A whose characteristic is hostility and aggression in interpersonal relations, is hereby confirmed as well. There is a possibility that these individuals are not able to put aside their negative 
feelings toward others and are involved in mental rumination of realities that have occurred in their relations. Thus, it is certain that they have lost their capability of real perception of relations and eventually, they are involved in more inner hostility compared to others. This is shown in the scores of pathologic type A. Although this conclusion would be made with more scrutiny, it so seems that reverse correlations of pathologic type A with all subscales of forgiveness indicate that both psychological variables and personality are effective in development of cardiovascular disorders. Beneficial effects of forgiveness on forgiver's health in the patients with cardiovascular disease may be related to its reverse correlation to hostility and inner anger of type A personality. ${ }^{2}$ Our finding is consistent with Waltman and his colleagues who reported that forgiveness intervention may be an effective means of reducing anger induced myocardial ischemia in patients with coronary artery disease. 18

Small sample size and extent of age range of the subjects in this study limits the possibility of more precise study of existing relations. Moreover, in this study, duration of disease has not been controlled. It is recommended that hierarchal studies would be used in the next researches and variables associated with disease such as type of consuming medicine and duration of disease would be controlled.

\section{Acknowledgements}

The author is thankful to Ms. Farahnaz Shirmardi for data collection.

\section{References}

1. Smith TW, MacKenzie J. Personality and Risk of Physical Illness. Annu Rev Clinic Psy. 2006;2:435-67.

2. Lawler-Row KA, Karremans JC, Scott C, Edlis-Matityahou M, Edwards L. Forgiveness, Physiological Reactivity and Health: the Role of Anger. Int J Psychophysiol. 2008;68(1):51-58.

3. Steptoe A, Molloy GJ. Personality and Heart Disease. Heart. 2007;93(7):783-84.

4. Carson JW, Keefe FJ, Goli V, Fras AM, Lynch TR, Thorp SR, Buechler JL. Forgiveness and Chronic Low Back Pain: a Preliminary Study Examining the Relationship of Forgiveness to Pain, Anger, and Psychological Distress. J Pain. 2005;6(2)84-91.
5. Enright RD, Gassin EA, Wu C. Forgiveness: A Developmental View. J Moral Educ. 1992;21:99-114.

6. Freedman SR, Enright RD. Forgiveness as an Intervention Goal with Incest Survivors. J Consult Clin Psychol. 1996;64:983-92.

7. Friedberg JP, Suchday S, Shelov DV. The Impact of Forgiveness on Cardiovascular Reactivity and Recovery. Int J Psychophysio. 2007;65:87-94.

8. Wallace HM, Exline JJ, Baumeister RF. Interpersonal Consequences of Forgiveness: Does Forgiveness Deter or Encourage Repeat Offenses? J Exp Soc Psychol. 2008;44:453-60.

9. Maltby J, Day L, Barber L. Forgiveness and Mental Health Variables: Interpreting the Relationship Using an Adaptational-Continuum Model of Personality and Coping. Pers Indiv Differ. 2004;37:1629-41.

10. Friedman M, Rosenman RH. Overt Behavior Pattern in Coronary Disease: Detection of Overt Behavior Pattern A in Patients with Coronary Disease by a New Psychophysiological Procedure. JAMA. 1960;173(12):1320-25.

11. Denollet J, Sys SU, Stroobant N, Rombouts H, Gillebert TC, Brutsaert DL. Personality as Independent Predictor of Long-term Mortality in Patients with Coronary Heart Disease. Lancet, 1996;347(8999):417-21.

12. Suls J, Bunde J. Anger, Anxiety, and Depression as Risk Factors for Cardiovascular Disease: the Problems and Implications of Overlapping Affective Dispositions. Psycholo Bull. 2005;131(2):260-300.

13. Ghorbani N. Relation of Hardiness, Behavioral Model A, and Disposed Behavior of Coronary Disease [thesis]. Tehran: Tarbiat Modarres University, Iran; 1994.

14. Booth-Kewley S, Friedman HS. Psychological Predictors of Heart Disease: A Quantitative Review. Psychol Bull. 1987;101(3):343-62.

15. Najarian B, Makvandi B, Dabbagh B, Nikfar S. Introduction and Validation of a Scale for Assessment of Type A Personality. J Educ Sci Psy Sh Chamran Ahv. 1995;1(1,2):24-50.[article in Persian]

16. Verdi M, Honarmand MM, Najarian B. Relationship between Perfectionism and Hardiness with Mental Health and Educational Achievement. J Educ Sci Psy Sh Chamran Ahv. 2001;3(1,2):51-70.[article in Persian]

17. Ehtesham M. Forgiveness and Mental Health [thesis]. Ahvaz: Islamic Azad University, Iran; 2008.

18. Waltman MA, Russell DC, Coyle CT, Enright RD, Holter AC, Swoboda MC. The Effects of a Forgiveness Intervention on Patients with Coronary Artery Disease. Psychol Health. 2009;24(1):11-27. 